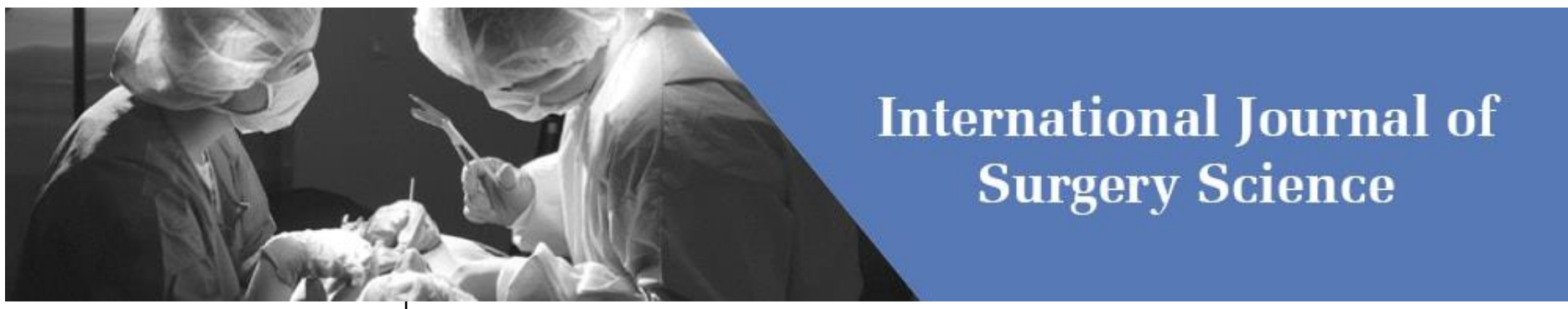

E-ISSN: 2616-3470

P-ISSN: 2616-3462

(C) Surgery Science

www.surgeryscience.com

2021; 5(2): 314-317

Received: 10-02-2021

Accepted: 12-03-2021

Dr. Safaa Ibrahim Kadhim

Chief of Urology Department,

Missan Alsader Teaching Hospital,

Iraq

\section{Effects of open prostatectomy on uroflowmetry parameters on patients having benign prostatic hyperplasia}

\section{Dr. Safaa Ibrahim Kadhim}

DOI: https://doi.org/10.33545/surgery.2021.v5.i2f.713

\section{Abstract}

Objective: to assess the effects of urinary flow rate/ uroflowmetry in patients with benign prostatic hyperplasia preoperatively and following open prostatectomy for three months post operatively.

Materials and Methods: this presoectine was done department of urological surgery AlSader Teaching Hospital between March 2010 to March 2016. Fifty consecutive patients age range 50 years to 80 years, on clinically diagnosed of benign prostatic hyperplasia $(\mathrm{BPH})$ were include in the study, preoperatively uroflowmetry is carried out followed by uroflowmetry post open prostatectomy, after first month, second month and third month.

Result: Mean age $63.62 \pm 6.75$ years Uroflowmetry parameter among fifty patients before operation are found, mean voiding time $32.37 \pm 19.19$ seconds, mean flow time $28.57 \pm 15.79$ seconds, mean time to maximum flow $9.64 \pm 6.65$ seconds, mean maximum follow rate $7.60 \pm 2.41 \mathrm{ml} / \mathrm{sec}$, mean overage flow rate $4.41 \pm 1.28 \mathrm{ml} / \mathrm{sec}$ and mean voided volume $165.54 \mathrm{ml}$. postoperative uroflowmetry was carried out after first month, second month and third month. The average of first three months of postoperative follow up uroflowmetry parameter obtained are, voiding time $27.64 \pm 11.67(\mathrm{P}=0.14)$ seconds, flowtime $25.72 \pm$ $11.00(\mathrm{P}=0.29)$ seconds, time to maximum flow $6.59 \pm 0.79(\mathrm{P}=0.05)$ seconds, maximum flow rate 27.24 $\pm 5.11(\mathrm{P}=0.001) \mathrm{ml}$ second, overage flowrate $13.48 \pm 2.08(\mathrm{P}=0.001) \mathrm{ml}$ second, voided volume 240.32 $\pm 49.91(\mathrm{P}=0.01) \mathrm{ml}$.

Conclusion: We conclude that the effects of post prostatectomy all the obstructive uroflowmetry parameters return more or less towards normal levels. As well as excellent improvements in both obstructive and irritative symptoms was also observed.

Keywords: BPH, uroflowmetry, hyperplasia

\section{Introduction}

Benign prostatic hyperplasia (BPH) is the most common disorder of the prostate gland. Histologic hyper plastic growth of prostate begins in approximately $40 \%$ of men aged 50 years and above. By age eighty, almost $90 \%$ of men have histological evidence of benign prostatic hyperplasia ${ }^{[1,2]}$. Patients with BPH have early clinical features like hesitancy, intermittency, frequency, nocturia, urgency, terminal dribbling, polyuria, difficulty in micturition, week urinary stream, incontinence of urine, and sometimes heamaturia ${ }^{[3]}$. Late clinical features will develop more serious sequelae of disease with urinary retention, recurrent urinary tract infection, bladder stone, bladder failure, renal dysfunction ${ }^{[4]}$.

These symptoms may be due to bladder outflow obstruction caused by Benign Prostatic Hyperplasia (BPH) or due to detrusor hyper - reflexia. The informative test to evaluate patients with Benign Prostatic Hyperplasia (BPH) is uroflowmetry. In spite of certain restrictions, uroflowmetry yields a high level of information, besides being a simple, at any time reproducible, and non - invasive procedure. Due to its low costs, it should be the primary step in diagnostics in the clinic as well as for practitioners ${ }^{[5,6,7,8]}$. The uroflowmetry which is done by an electronic instrument to calculate the velocity of urine flow. Uroflowmetry results in a normal 70 - years old with no evidence of BPH has average flow rate of $12 \mathrm{ml} / \mathrm{sec}$ and peak flow rate close to $20 \mathrm{ml} / \mathrm{sec}$ having at least $125-150 \mathrm{ml}$ in the bladders, with mild enlarged $\mathrm{BPH}$ has average flow rates $6-8 \mathrm{ml} / \mathrm{sec}$ and $11-15 \mathrm{ml} / \mathrm{sec}$ peak flow rate and severe enlarged $\mathrm{BPH}$ has further decrease flow rates 9 . 


\section{Material and Methods}

This prospective study was conducted at department of Urological Surgery Al - Sadr Teaching Hospital between March 2010 to March 2016. These fifty consecutive patients with benign prostatic hyperplasia $(\mathrm{BPH})$ were included in the study. Pre operatively ureflowmetry was carried out followed by Uroflometry post.prostetactomy and their results were co related. The age range of the patients included in the study was 50 to 80 years. The average was 63.62 years. (see table No. 1)

\section{Inclusion Criteria}

Only those patients who presented with lower urinary tract symptoms due to enlarged prostate but neither have developed retention of urine, nor catheterized were included in this study.

\section{Exclusion Criteria}

Following patients were excluded from study:

1. With carcinoma prostate.

2. With urethral stricture.

3. With bladder neck stricture.

4. With diabetes mellitus.

5. Patients taking drugs for BPH.

6. Catheterized patients.

7. With bladder atonia.

8. urinary incontinenc

Age of the patients

Total No. of patients $=50$

Age range: $50-80$ years

Average age: 63.62 years

Table 1: Age of patients

\begin{tabular}{|c|c|c|}
\hline Age range in year & No. of patients & Percentage \\
\hline $50-55$ & 5 & $10 \%$ \\
\hline $56-60$ & 17 & $34 \%$ \\
\hline $61-65$ & 7 & $17 \%$ \\
\hline $66-70$ & 14 & $28 \%$ \\
\hline $71-75$ & 5 & $10 \%$ \\
\hline $76-80$ & 2 & $4 \%$ \\
\hline
\end{tabular}

Weight of prostatic gland (Ultrasound) Minimum weight of prostate $=37 \mathrm{mIs}$ Maximum weight of prostate $=77 \mathrm{mIs}$ Average weight of prostate $=60.46 \mathrm{mIs}$

Table 2: Weight of prostate

\begin{tabular}{|c|c|c|}
\hline Weight of prostate in mIs & No. of patients & Percentage of patients \\
\hline $1-30$ & 0 & $0 \%$ \\
\hline $31-40$ & 3 & $6 \%$ \\
\hline $41-50$ & 8 & $16 \%$ \\
\hline $51-60$ & 13 & $26 \%$ \\
\hline $61-70$ & 19 & $38 \%$ \\
\hline $71-80$ & 7 & $14 \%$ \\
\hline
\end{tabular}

Pre - operative uroflowmetry parameters

Pre - operative parameters

Table 3: Uroflowmetry Parameters

\begin{tabular}{|c|c|}
\hline Voiding time $(\mathrm{n}=50)$ & $32.27 \pm 19.19$ seconds $(27.5)$ \\
\hline Flow time $(\mathrm{n}=50)$ & $28.57 \pm 15.76$ seconds $(24.0)$ \\
\hline Time to max: Flow $(\mathrm{n}=50)$ & $9.64 \pm 6.65 \mathrm{~seconds}(6.00)$ \\
\hline Max: Flow rate $(\mathrm{n}=50)$ & $7.60 \pm 2.41 \mathrm{ml} / \mathrm{sec}(7.5)$ \\
\hline Average flow rate $(\mathrm{n}=50)$ & $4.44 \pm 1.28 \mathrm{ml} / \mathrm{sec}(4.55)$ \\
\hline Voided volume $(\mathrm{n}=50)$ & $165.54 \pm 49.60 \mathrm{ml}(170.0)$ \\
\hline
\end{tabular}

\section{Pre-operative assessments}

A care full history especially about the symptoms was taken in all fifty patients. A through physical digital rectal examination of the prostate gland was done. All the necessary investigations including ultrasound $\mathrm{KUB}, \mathrm{X}$ - ray $\mathrm{KUB}$, blood $\mathrm{CP}$ and group urine $\mathrm{DR}$, urine $\mathrm{C} / \mathrm{S}$, renal function tests and blood sugar were carried out. In selected patients intravenous urography and prostatic specific antigen (PSA) was also done. Anesthesia fitness was taken. The average weight of prostate gland on ultrasound finding was $60.46 \mathrm{mIs}$ while minimum weight of prostate gland $34 \mathrm{mIs}$. (see table No. 2).Majority of patients were operated under spinal anesthesia and in few patients under general anesthesia. Foleys catheter removed on tenth Or twelve day post operatively. Patients were discharged with adequate urinary flow.

\section{Post-operative follow up studies}

The follow up studies were done for three months after removal of catheter post - operatively on following periods, with uroflowmetry, after first, second and third month of removed of catheter.

\section{Results}

\section{Pre-operative uroflowmetry parameters}

Among fifty patients before operation the mean voiding time was found $32.37 \pm 19.19 \mathrm{sec}$ (mean \pm S.D), median time was $27.5 \mathrm{sec}$, The mean flow time was found $28.57 \pm 15.79 \mathrm{sec}$ (mean \pm S.D), median time was $24.0 \mathrm{sec}$. The mean time to maximum flow was $9.64 \pm 6.65 \mathrm{sec}($ mean \pm S.D), median time $6.0 \mathrm{sec}$. The mean maximum flow rate was $7.60 \pm 2.41 \mathrm{ml} / \mathrm{sec}$ (mean \pm S.D), median value $7.5 \mathrm{ml} / \mathrm{sec}$. The mean average flow rate was $4.44 \pm 1.28 \mathrm{ml} / \mathrm{sec}$ (mean \pm S.D), median value 4.44 $\mathrm{ml} / \mathrm{sec}$. The mean voided volume was $165.54 \pm 49.60 \mathrm{ml}$ (mean \pm S.D), median value $170.0 \mathrm{ml}$, (Table: 3 ).

Post - operative follow up (after first month, second month and third month) uroflowmetry parameters:

At the end of the first to third month of operation mean voiding time of fifty patients was $28.26 \pm 14.68 \mathrm{sec}, 27.08 \pm 11.12 \mathrm{sec}$ and $27.75 \pm 12.01 \mathrm{sec}$ respectively with median values were 25 seconds. The average of first three months post - operative was $27.64 \pm 11.67 \mathrm{sec}$ with median value $27.64 \mathrm{sec}$. The change in average time from first to third month of operation was found statistically non - significant with $P>0.014$, when tested by $\mathrm{F}-$ Statistics.

Mean flow time of fifty patients from first to third month was $26.1 \pm 13.2 \mathrm{sec}, 25.12 \pm 10.70 \mathrm{sec}$ and $26.14 \pm 11.27 \mathrm{sec}$ respectively and their median values were $23.5,22.5$ and 23.5 sec respectively. The average of first three months of post operative follow up was $23.33 \mathrm{sec}$. The change in average time from first to third month of operation was found statistically non - significant with $P>0.29$

The mean time to maximum flow of fifty patients from first to third month $6.48 \pm 1.19 \mathrm{sec}, 6.64 \pm 1.08 \mathrm{sec}$ and $6.85 \pm 1.10 \mathrm{sec}$, with their median values $7 \mathrm{sec}, 7 \mathrm{sec}, 7 \mathrm{sec}$ respectively. The average of the first three months of the post - operative was 6.59 $\pm 0.79 \mathrm{sec}$. The change in average time from first to third month if operation was found statistically significant with $P<0.05$.

At the end of the first, second and third month of operation, mean maximum flow rate of fifty patients was $26.03 \pm 7.15$ $\mathrm{ml} / \mathrm{sec}$ with median value $26.45 \mathrm{ml} / \mathrm{sec}, 27.5 \pm 5.33 \mathrm{ml} / \mathrm{sec}$ with median value $27.55 \mathrm{ml} / \mathrm{sec}, 37.39 \pm 4.91 \mathrm{ml} / \mathrm{sec}$ respectively. The average of first three months post - operative follow up was $27.24 \pm 5.1 \mathrm{ml} / \mathrm{sec}$. The change in average from first month to third month of operation was found statistically significant with 
$P<0.001$

The main average flow rate of fifty patients in first, second and third months was $12.66 \pm 3.0 \mathrm{ml} / \mathrm{sec}$, with median value 12.45 $\mathrm{ml} / \mathrm{sec}, 13.69 \pm 2.53 \mathrm{ml} / \mathrm{sec}$ with median value $13.2 \mathrm{ml} / \mathrm{sec}$ and $13.76 \pm 2.05 \mathrm{ml} / \mathrm{sec}$ with median value $13.5 \mathrm{ml} / \mathrm{sec}$ respectively. The average of first three months of post - operative follow up was $13.48 \pm 2.08 \mathrm{ml} / \mathrm{sec}$, with median value $13.17 \mathrm{ml} / \mathrm{sec}$. The change in average from first to third month of operation was found statistically significant with $P<0.01$.
From first to third month of operation mean voided volume was $234.20 \pm 70.44 \mathrm{ml}$ with median value $210 \mathrm{ml}, 249 \pm 77.63 \mathrm{ml}$ with median $230 \mathrm{ml}$, and $234.58 \pm 38.22 \mathrm{ml}$ with median 230 $\mathrm{ml}$. the average of first three months of post - operative follow up was $240.32 \pm 49.91 \mathrm{ml}$, with median value $231.00 \mathrm{ml}$. The change in average from first month to third month of operation was found statistically significant with $P<0.01$, (See Table No: $4)$.

Table 4: Post - operative uroflowmetry parameters $(n=50)$

\begin{tabular}{|c|c|c|c|c|}
\hline Parameters & First month follow up & First month follow up & First month follow up & Average of three follow up \\
\hline Voiding time $(\mathrm{n}=50)$ & $28.26 \pm 14.68(22.50)$ & $27.08 \pm 11.12(26.0)$ & $27.75 \pm 12.01(25)$ & $\begin{array}{c}27.64 \pm 11.67(27.64) \\
P>0.14 \\
\mathrm{~T}=1.48\end{array}$ \\
\hline Flow Time $(\mathrm{n}=50)$ & $26.1 \pm 13.20(23.5)$ & $25.12 \pm 10.70(22.50)$ & $26.14 \pm 11.27(23.5)$ & $\begin{array}{c}25.72 \pm 11.00(23.33) \\
P>0.29 \\
\mathrm{~T}=1.05\end{array}$ \\
\hline Time to Max Flow $(n=50)$ & $6.48 \pm 1.17(7.00)$ & $6.64 \pm 1.08(7.0)$ & $6.58 \pm 1.10(7.00)$ & $\begin{array}{c}6.59 \pm 0.79(6.33) \\
P<0.05 \\
\mathrm{~T}=3.06\end{array}$ \\
\hline Max: Flow Rate $(\mathrm{n}=50)$ & $26.03 \pm 7.15(26.45)$ & $27.53 \pm 5.33(27.55)$ & $37.39 \pm 4.91(27.25)$ & $\begin{array}{c}27.24 \pm 5.11(26.9) \\
P<0.001 \\
\mathrm{~T}=23.12\end{array}$ \\
\hline Average Flow rate $(n=50)$ & $12.66 \pm 3.01(12.45)$ & $13.69 \pm 2.53(13.2)$ & $13.76 \pm 2.05(13.5)$ & $\begin{array}{c}13.48 \pm 2.08(13.17) \\
P<0.01 \\
\mathrm{~T}=24.33\end{array}$ \\
\hline Voided Volume & $234.20 \pm 70.44(210)$ & $249.79 \pm 77.63(230)$ & $234.58 \pm 38.22(230)$ & $\begin{array}{c}240.32 \pm 49.91(231.0) \\
P<0.01 \\
\mathrm{~T}=7.44\end{array}$ \\
\hline
\end{tabular}

\section{Discussion}

Benign prostatic hyperplasia is a disease of old men which leads urinary problems due to effects on both obstructive and irritative symptoms of enlarged prostate such as hesitancy, frequency, urgency, dribbling of urine and dysuria make the troublesome life style, especially during night times. Patients with lower urinary tract symptoms generally seek help for relief of their symptoms and the best indicator for the successful treatment is relief of symptoms14._In the present study, preoperative maximum flow rate (Qmax) was found to be $7.6 \mathrm{ml} / \mathrm{sec} \pm 2.41$. This rate is $9.5 \mathrm{ml} / \mathrm{second}$, and $7.1 \mathrm{ml} / \mathrm{second}$ reported by Nielsen - KT et al (1989) ${ }^{[15]}$ and Larosa M. et al. (1993) ${ }^{[19]}$ respectively ${ }^{[18,19]}$. These findings are more or less similar to that of our study._It has been observed that in all patients there was obstructed symptom and significantly reduced maximum flow rate pre operatively._In a study by Nielsen - KT et al (1989) ${ }^{[15],}$ maximum flow rate at three months follow up is found to be $17.0 \mathrm{ml}$ per second in 84 consecutive patients. In other study by Dorflinger $-\mathrm{T}$ et al (1988) ${ }^{[20]}$ at three months follow up, the maximum flow rate $21.5 \mathrm{ml} / \mathrm{second}$ in nineteen patients 20 . The average of first three months post - operative follow up of our patient $(27.24 \pm 5.11 \mathrm{ml} / \mathrm{sec})$ was significantly improved like those reported by above mentioned workers, the flow rate in these studies remains stable throughout the follow up period. Among the uroflowmetry parameters analyzed, the best correlation was observed between the degree of prostatic obstruction and the degree of maximum flow rate (Qmax) 21._In the present group the pre - operative average flow rate was found to be $4.44 \pm 1.28 \mathrm{ml} / \mathrm{second}$ and average first three months of post - operative follow up was $13.48 \pm 2.08$ $\mathrm{ml} / \mathrm{second}$._I is analyzed that there is significant improvement in average flow rate after open prostatectomy in comparison to pre - operative._The rest of the uroflowmetry parameters in respect to patients with benign prostatic hyperplasia are not well documented, but we are of opinion that significant improvement also occur in other parameters as well.

\section{Conclusion}

We concluded that the effects of open prostatectomy on uroflowmetry parameters are significantly improved postoperatively. Our study indicates that there is excellent improvement in the maximum flow rate, average flow rate in all postoperative follow up visits._We are of opinion that open prostatectomy is still gold standard in improving the obstructive symptoms of benign prostatic hyperplasia.

\section{References}

1. McKelive GB, Collins GN, Hehir M. Rogers CN. A study of benign prostatic hyperplasia. A challenge to British urology. Br J Urol 1993;71:38-42.

2. Grino PB, Bruskewitz R, Blaivas JG, et al. maximum urinary flow rate by uroflowmetry: Automatic or visual interpretation. J Urol 1993;149(3):339-341.

3. Harding Rains AJ, Charles V. Manna Baily and Love's, short practice of surgery 20th Ede: 1299-1308.

4. Paul C Peters, Timothy B Boone, Irwin N Frank, John D, MC Conell, Glenn M. Preminger. Schwaetz: Principles of surgery, 6th ede 1998;9:1753-55.

5. Karl C, Gerlach R, Hannppel J, Lehnen H. Investigation of Pre and postoperative measurements. Urol, ink 1986;41(4):270-75.

6. Jensen KM-E, Jorgensen JB, Mogensen P: Reproducibility of uroflowmetry in variables in elderly males. Urol Res 1985;13:237-239.

7. Drach GW, Steinbronn DV. Clinical evaluation of patients with prostatic obstruction: correlation of flow rates with voided, residual or total bladder volume. J Urol 1986;135(4):737-40. 
8. Gotoh M, Yoshikawa Y, Kondo A, Kato N, Ono Y, Kondo $\mathrm{T}$, et al. Diagnostic values and limitations of conventional urodynamic studies (uroflowmetry residual urine measurement cystometry) in benign prostatic hypertrophy. Nippon Hinyokika Gakkai Zasshi 1996;87(12):1321-30.

9. Emill A, Tanagho, Jack W. McAninch Smith's, General Urology, 14th Ede 1996, 400-401.

10. Blaivas JG, Chancellor MB. Transurethral incision of the prostate: At alternative to prostatectomy. Prob In Urol 1991;5(3):412-417.

11. Tanaka Y, Masumori N, Tsukamoto T, Furuya S, Furuya R, Ogura H. Long-term results of lower urinary tract symptoms and urinary flow rate after transurethral resection of the prostate. Hinyokika Kiyo 2007;53(6):369-73.

12. Bar K. Evaluation of uroflowmetry in different groups of patients after transurethral resection of prostatic adenoma. Int - Urol - Nephrol (4):345-50.

13. Kojima M, Hayakawa T, Saiito T, Mitsuya H, Hayase Y. Age - related changes in lower urinary tract symptoms and urodynamic parameters in patients with benign prostatic hyperplasia treated by transurethral resection of the prostate. Nippon Hinyokika Gakkai Zasshi 2001;92(4):513-9.

14. Frimodt-Moller PC, Jensen KME, Iversen P, madsen PO, Bruskewitz RC. Analysis of presenting symptoms in prostatism. J. Urol 1984;132:272-276.

15. Iqbal $\mathrm{T}$. History of benign prostatic disease and result in: urodynamic study of symptoms of benign prostatic disease (thesis). Lahore: University of the Punjab 1988, 4-15 and 104-134.

16. Saleem M. postoperative evaluation of symptoms and complications following transurethral resection of the prostate gland (thesis). Lahore: university of the Punjab 1992, 65-81.

17. Mebusut WK, Holtgrewe HL, Cockett ATK, Peters PC. and writing committee. Transurethral prostatectomy: Immediate and postoperative complications. A cooperative study of 13 participating institutions evaluating 3885 patients. J Urol 1989;141:243-247.

18. Nielsen KT, Christensen MM, Madsen PO, Bruskewitz RC. Symptom analysis and uroflowmetry 7 years after transurethral resection of the prostate. J Urol 1989;(5):12513.

19. Larosa M; Ferretti S; Salsi P; Simonazzi M. Uroflowmetry in the assessment of patients with benign prostatic hyperplasia. Acta, Biomed Atenco Parmense 1993;64(12):17-22.

20. Dorflinger T, England DM, Madsen PO, Bruskewitz RC. Urodynamic and histological correlates of benign prostatic hyperplasia. J Urol 1988;140(6):1487-90.

21. Gotoh M. Surgery (TUR - P) as a recommended initial treatment modality for the presented case. Hinyokika Kiyo 2005;51(9):603-8. 